\title{
CFD ANALYSIS TO DEMONSTRATE IN VESSEL RETENTION INDUCING A BYPASS FLOW
}

\section{TOBIAS STRÖMGREN ${ }^{1}$, YANN LE MOIGNE ${ }^{1}$, DONG-YUAN SHENG ${ }^{1}$ AND CHRISTOPH HARTMANN²}

\author{
${ }^{1}$ Westinghouse Electric Sweden AB \\ 72163 Västerås, Sweden \\ stromgts@westinghouse.com \\ ${ }^{2}$ Westinghouse Electric Germany GmbH \\ Dudenstraße 6 \\ 68167 Mannheim, Germany
}

Key words: CFD, Critical Heat Flux, Boiling.

\begin{abstract}
The goal of this work is to design a nozzle system around the Reactor Pressure Vessel (RPV) of a VVER-1000 nuclear reactor which would ensure successful melt retention during a severe accident. Simulations were performed with a multiphase model in ANSYS Fluent 19.1 to determine this. The results suggest that an efficient cooling can be achieved by inducing a flow rising parallel to the RPV walls in the flooded reactor cavity. In order to do this, it is proposed to use one central nozzle below the RPV and a ring of 32 nozzles $0.5 \mathrm{~m}$ above the RPV bottom. Assuming a 2 bar pressure, injection of $750 \mathrm{~m}^{3} / \mathrm{h}$ water at $80^{\circ} \mathrm{C}$ through the nozzles led to little steam production and a heat flux below the critical value.
\end{abstract}

\section{INTRODUCTION}

In-Vessel Retention (IVR) is a severe accident mitigation measure that could be implemented to VVER-1000 reactor designs by flooding the reactor cavity when the reactor core has melt. Successful implementation of IVR requires that the Critical Heat Flux (CHF) is not reached at the outer surface of the Reactor Pressure Vessel (RPV).

$\mathrm{CHF}$ occurs when a stable vapour layer covers a section of the heated wall. Since vapour has a lower heat transfer coefficient than liquid, the wall temperature has to increase in order to maintain the imposed heat flux. The large wall temperatures are a safety concern since they could reach the melting point of the RPV wall.

In this work, the CHF is estimated with the correlations proposed by $[6,7]$ for the curved geometry of the RPV (Figure 1a)

$$
q_{C H F}(\theta)=490-30.2 \theta-8.8 e^{-1} \theta^{2}+1.35 e^{-2} \theta^{3}-6.65 e^{-5} \theta^{4}
$$

where $\theta$ is the wall angle: $0^{\circ}$ for horizontal direction and $90^{\circ}$ for vertical direction. Eq. (1) was obtained using saturated water in a natural circulation environment. However, experimental data shows that the CHF increases quasi-linearly with the fluid velocity and 
subcooling [2,3] (Figure 1b). Therefore, Eq. (1) provides a conservative estimate since the fluid velocities and subcooling induced by the nozzle system proposed in this work are expected to increase the $\mathrm{CHF}$.

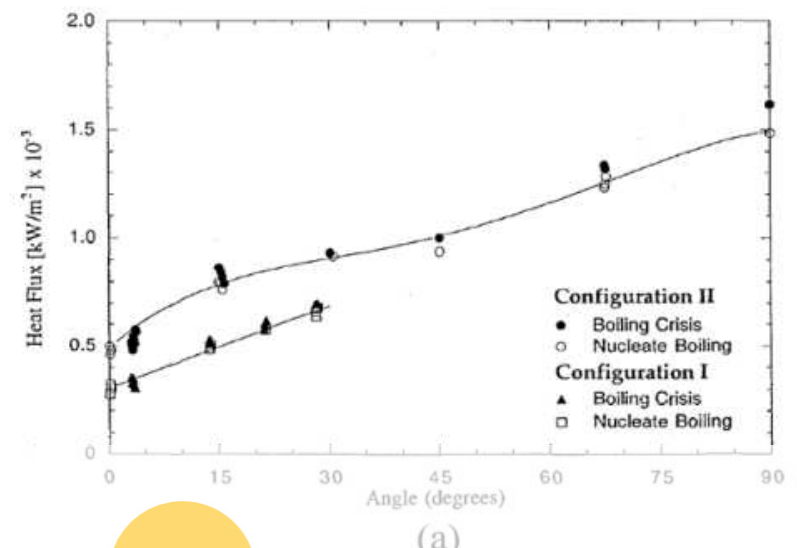

Figure 1: Experimental measurements of the $\mathrm{CHF}$ as a function of: (a) wall angle at $0{ }^{\circ} \mathrm{C}$ subcooling - Figure taken from [4] (T.G. Theofanous, et. al., 1997). The fitting line shown in (b) for Configuration II corresponds to (1). (b) Subcooling - Figure taken from [9] (Ono and Sakashita, 2009).

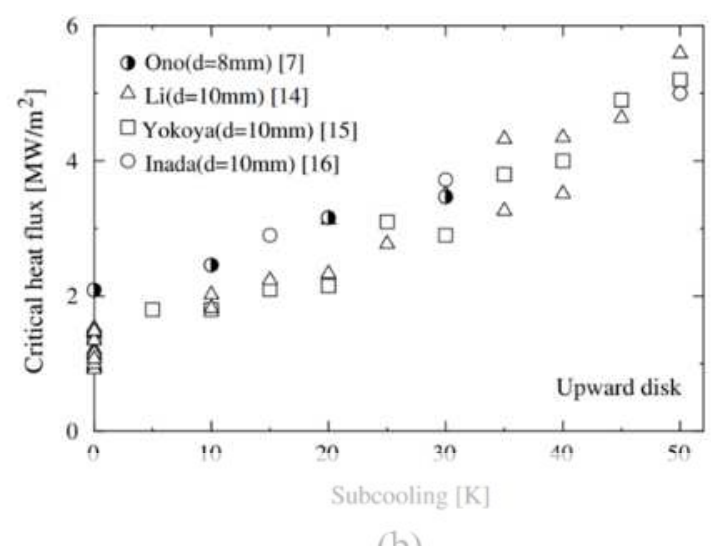

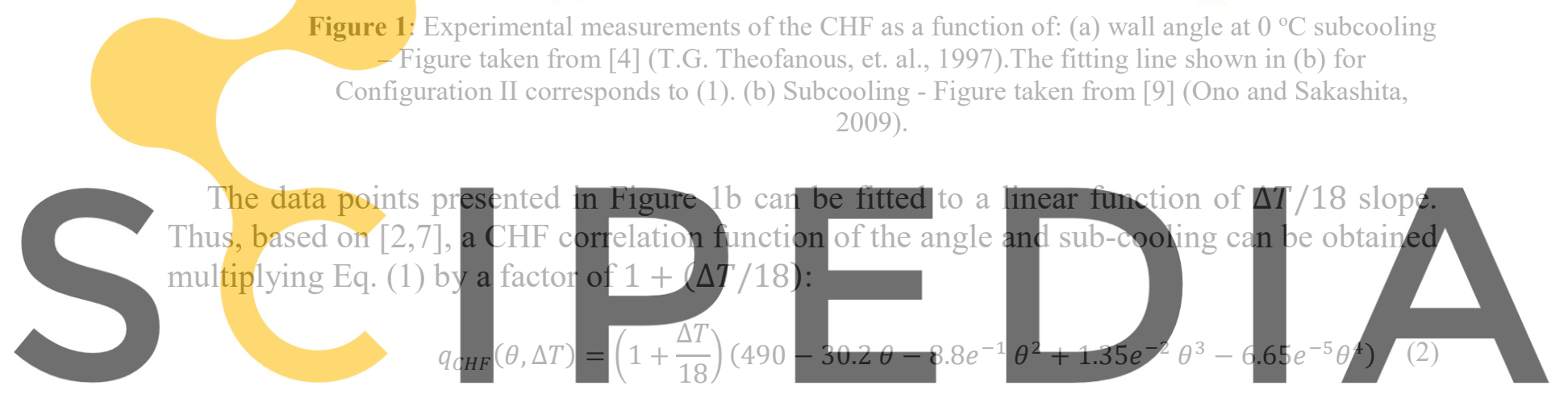

Developing a new CHF correlation is beyond the scope of this work, especially because its

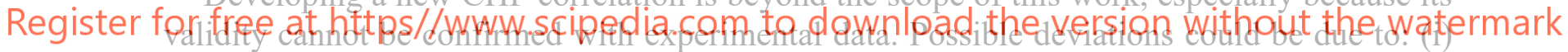
non-linearities between CHF and the sub-cooling; (ii) the smaller scale of the experiments form Figure ib compared to the large scale of the RPV and (iii) different behaviour of the CHF to sub-cooling at angles $\theta$ different than $90^{\circ}$. Despite these uncertainties, Eq. (2) is included in the report to enable an approximate estimate on the required cooling conditions of the nozzle system.

\section{ESTIMATED SUBCOOLING AND MASS FLOW RATES}

The heat fluxes at the inner and outer walls of the RPV obtained with the ASTEC code are presented in Figure 2. Comparison with the CHF correlation given by Eq. (1) suggests that cooling the outer walls with saturated water $\left(0^{\circ} \mathrm{C}\right.$ subcooling $)$ might not be sufficient to avoid CHF. Based on Eq. (2) and on the heat flux at the inner wall of the RPV, the subcooling needed to avoid CHF is estimated to be $40^{\circ} \mathrm{C}$. The outer wall of the RPV presents a lower heat flux since part of the inner heat is transferred to the gas space inside the RPV through convection and radiation (note that in the ASTEC calculations the flux at the inner wall of the RPV corresponds to the total heat stored in the melt pool). For the outer flux, the subcooling 
needed to avoid CHF would be $20^{\circ} \mathrm{C}$. Nevertheless, we propose to use the conservative estimate of $40^{\circ} \mathrm{C}$ to (i) account for possible errors from the analytical correlations and (ii) to consider the total heat which could potentially be transferred to the outer wall of the RPV.

It should be noted that the values of the sub-cooling estimated in this section are obtained assuming no flow velocity (i.e. no nozzle system inducing a high velocity flow around the RPV). This is a conservative assumption since larger flow velocities are expected to increase the margin to CHF [2,3]. Moreover, the validity of Eq. (2) should be further verified against experimental data.

The mass flow $\dot{m}$ required to cool the vessel can be estimated equating the total heat from the walls $Q_{\text {walls }}$ to the heat which can be absorbed by the liquid without requiring a phase change to steam, Eq. (3). Production of steam through nucleate boiling is considered to be an efficient mechanism of heat transfer removal which should not pose a threat to the RPV integrity. Therefore, the estimate from Eq. (3) should be considered as a rough estimate for the order of magnitude of the nozzle flow rate.

$$
Q_{\text {walls }}=\dot{m} c_{p}\left(T_{\text {nozzle }}-T_{\text {sat }}\right)
$$

The results from Eq. (3) are presented in Figure 3. The colorbar represents the ratio between $Q_{\text {walls }}$ and the cooling $\dot{m} c_{p} \Delta T$. Ratios larger than 1 require producing steam to remove the heat; whereas values lower than 1 would minimize the steam production. It should be noted that the estinate from Eq. (3) considers the total heat, not its spatial variation. Thus, larger heat flows than production at the region

Based on Figure 2

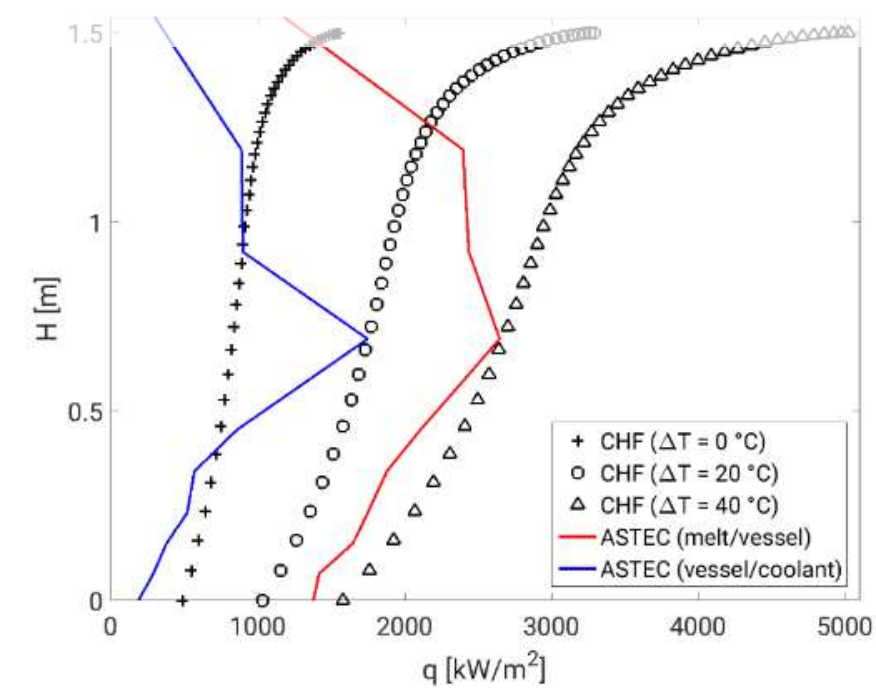

Figure 2: Expected CHF at different sub-cooling values (obtained with (2)) and comparison to the heat fluxes computed in the ASTEC simulations for $70 \mathrm{t}$ of steel. 


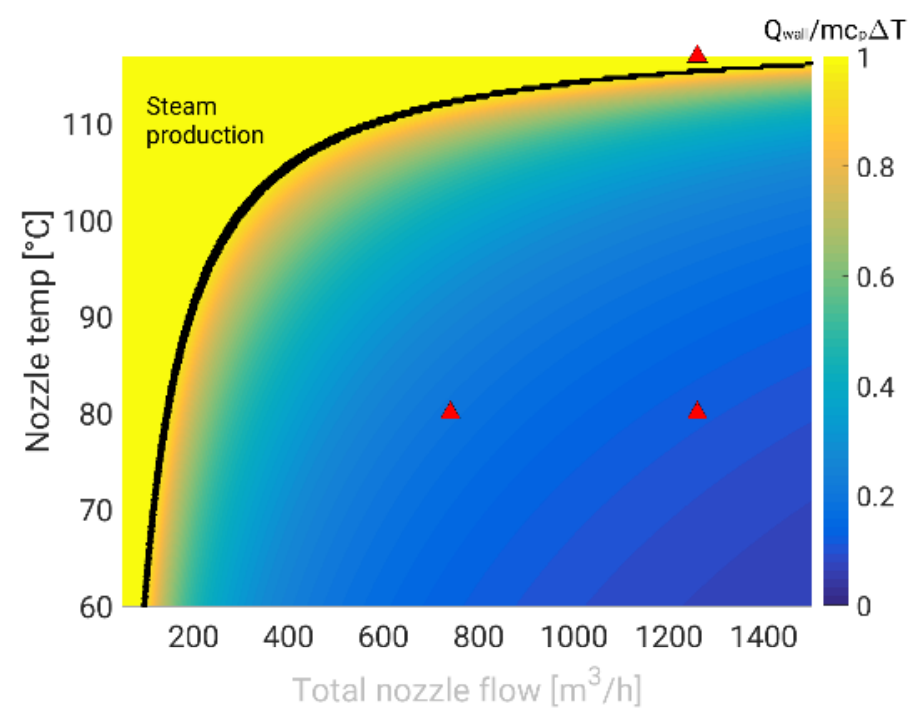

Figure 3: Boundary obtained with (3). The ( $\boldsymbol{\Delta})$ markers denote the conditions analyzed with CFD in Section 4 and ( - ) the boundary where the heat ratio equals to one.

\section{CFD CASE SETUP}

The CFD code of ANSYS Eluent 19.1 is used to determine the optimal nozzle distribution

to cool the RPV walls. nozzle design (Section 4)

3.1 Geometry

The geometry of the RPV walls was simp
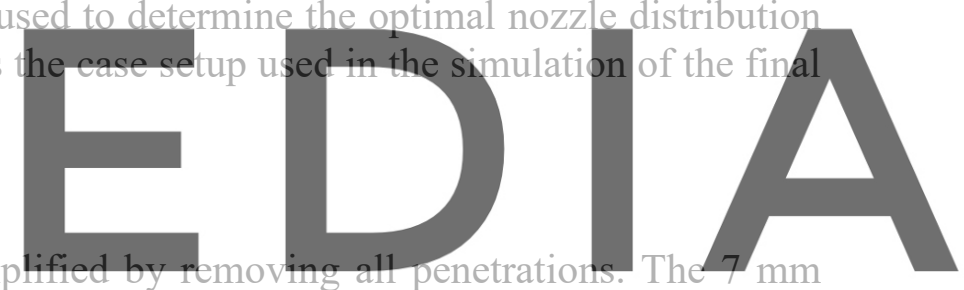

inner layer of stainless steel was also neglected. Thus, the RPV walls were modelled with a

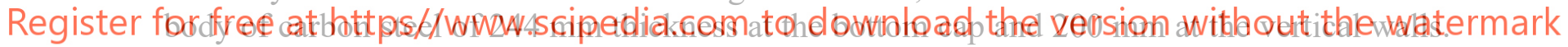

The simplification of the stainless steel will lead to a very small over prediction of the thermal conductivity in the material and is judged not to have an impact on the results.

\subsection{Mesh}

The mesh was built in ANSA with hexahedral elements using a multi-block approach, see Figure 4. In the fluid region, five layers of cells with $0.4 \mathrm{~mm}$ thickness were added at the RPV walls. Beyond these layers, the cell sizes were increased using a constant expansion ratio of 1.1. The cell sizes in the rest of the domain were kept at about $20 \mathrm{~mm}$. The corner of the quarter 3D mesh cannot be meshed with hexahedral elements. Therefore, this region was meshed with a prism cells transition as shown in the details from Figure 4.

The $0.4 \mathrm{~mm}$ cell size at the RPV walls led to an average $\mathrm{y}^{+}$of about 12 . Maximum $\mathrm{y}^{+}$ values of 110 were observed at the impingement point of the nozzle flow on the RPV walls. These values are considered to be a middle ground between the $y+$ values of 30-40 needed for an efficient vapour removal in boiling regimes; and the $y+$ values of 1-5 needed for resolving the viscous sub-layer in Conjugate Heat Transfer (CHT). For example, simulations performed in [10] using boiling and CHT models show that using a $\mathrm{y}+$ of 13-36 leads to a closer 
agreement to experimental data than when refining the mesh to $y+$ values of $0.6-4.1$.

The interface between the solid and liquid regions was modelled with a conformal mesh (same nodes shared by the solid and liquid at the interface). This approach is expected to be more efficient and accurate compared to non-conformal meshes since it does not require interpolating at the interface. In the solid, the cell size in the first layer near the fluid, where larger temperature gradients are expected, was set to $1 \mathrm{~mm}$. With these settings, the 3D quarter meshes had a total of 4.1 million cells ( 3.43 million in the fluid and 0.67 million in the solid).

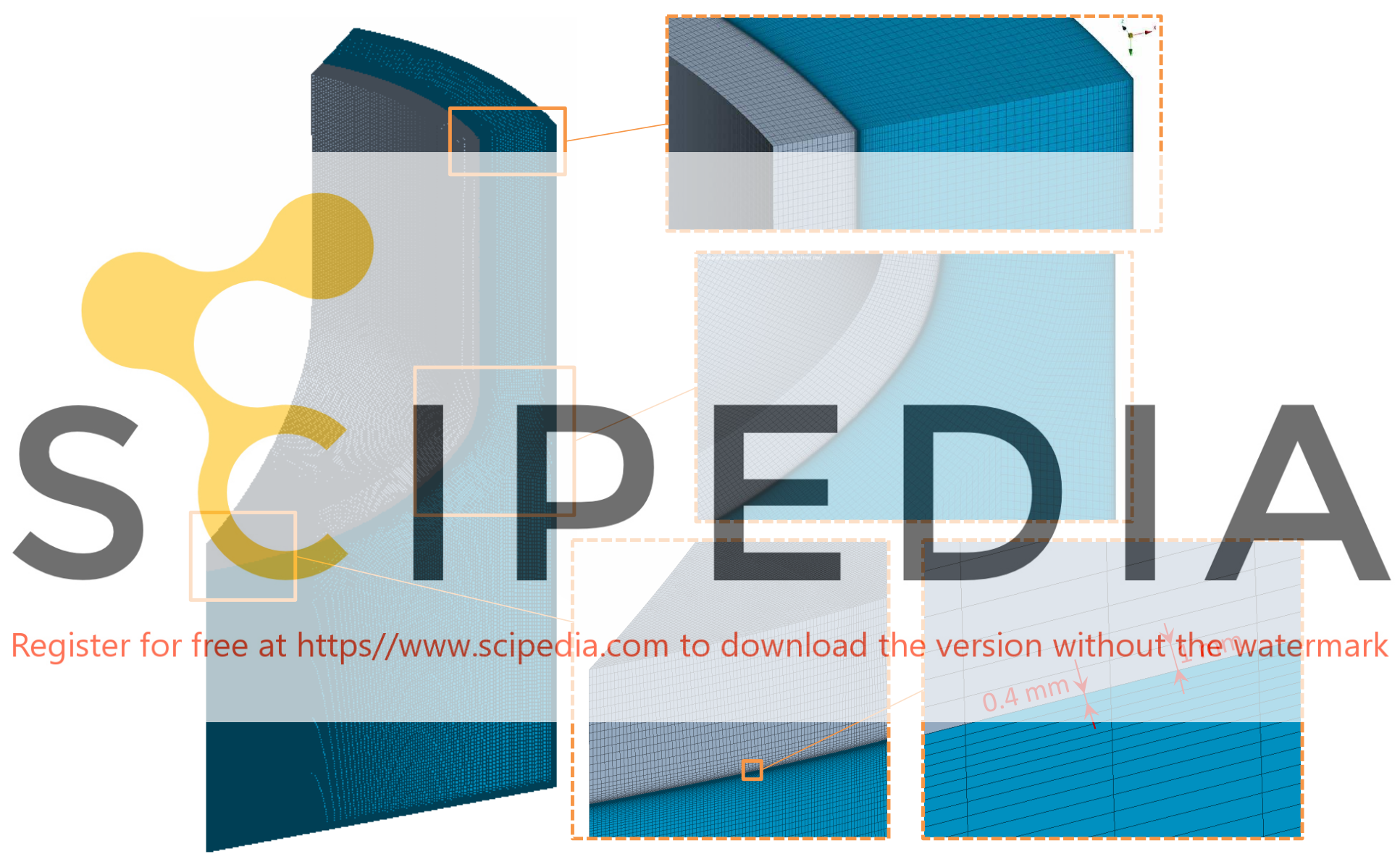

Figure 4: Over-view of the quarter 3D mesh generated with ANSA. The blue and gray colors denote the fluid and solid domains, respectively.

\subsection{Initial and boundary conditions}

All the simulations were run assuming a pressure of 2 bar, equivalent to a saturation temperature of $120^{\circ} \mathrm{C}$. Accident scenarios leading to other pressures are also possible, but these are not considered in the present report.

The heat flux applied at the inner side of the RPV walls was taken from the ASTEC calculations (Table 1). Linear interpolation was assumed between the data points. Above the melt pool the heat flux was set to zero. The cavity walls were modelled as adiabatic.

The fluid volume around the RPV can swell during the transient due to density changes in 
the liquid and production of steam near the wall. To accommodate such expansions, the pool surface was modelled as a pressure outlet boundary condition.

Table 1: Heat flux along the corium/vessel side of the RPV walls obtained for the case of $70 \mathrm{t}$ of molten steel. Zero elevation corresponds to the bottom of the inner vessel wall.

\begin{tabular}{cc}
\hline Elevation $[\mathrm{m}]$ & Heat flux $\left[\mathrm{MW} / \mathrm{m}^{2}\right]$ \\
\hline 0 & 1.38 \\
\hline 0.07 & 1.42 \\
\hline 0.15 & 1.65 \\
\hline 0.32 & 1.75 \\
\hline 0.34 & 1.88 \\
\hline 0.45 & 2.11 \\
\hline 0.69 & 2.65 \\
\hline 0.92 & 2.44 \\
\hline 1.19 & 2.40 \\
\hline 1.54 & 1.18 \\
\hline
\end{tabular}

The heat and momentum sources induced by the nozzle ring were added to the fluid region using User Defined meaning that the injected the UDF. The energy
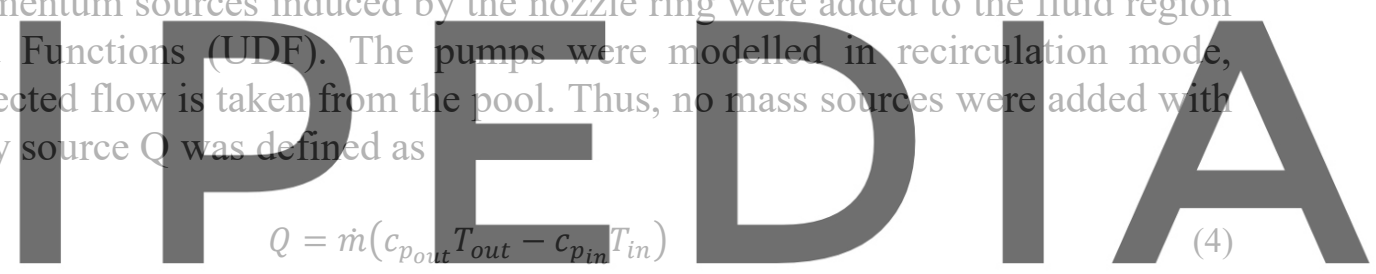

Register for free at https//www.scipedia.com to download the version without the watermark where the specific heat $\mathrm{c}_{\mathrm{p}}$ and temperature $\mathrm{T}$ at the inlet were computed every time step as the average value of the cells behind and in-line with the momentum source. For the current calculations the outlet temperature of $\mathrm{T}_{\text {out }}$ was taken as 117 and $80^{\circ} \mathrm{C}$, respectively.

The heat and momentum sources were distributed radially symmetrically around the vessel axis. The volume of the cells where the sources was applied was based on the assumed nozzle diameter. For example, for a $75 \mathrm{~mm}$ diameter nozzle, the sources were applied over a group of cells with $66.5 \times 66.5 \mathrm{~mm}$ area and $10 \mathrm{~mm}$ height.

\subsection{Material properties}

Some of the water properties were defined as polynomial function of the liquid temperature using IAPWS-IF97 data. The steam and steel properties were defined constant.

\subsection{Models and numerical setup}

The simulations were run in ANSYS Fluent 19.1 using an Eulerian multiphase model. In this model, independent mass, momentum and energy equations are solved for the vapour and liquid phases; and analytical correlations are used to model the mass, momentum and energy 
exchange between them. The temperature in the RPV walls was modelled with the heat conduction equation. Deformation of the RPV walls was not calculated.

Boiling at the RPV walls was calculated using non-equilibrium Rensselaer Polytechnic Institute (RPI) model (Eq. (5)), which is an extension of the original RPI model which enables computing saturated boiling.

$$
q_{w}=\left(q_{c}+q_{q}+q_{e}\right) f\left(\alpha_{L}\right)+q_{v}\left(1-f\left(\alpha_{L}\right)\right)
$$

In this model, the total heat transfer from the wall $\mathrm{q}_{\mathrm{w}}$ is computed as the summation of heat conduction to the liquid $\mathrm{q}_{\mathrm{c}}$, quenching $\mathrm{q}_{\mathrm{q}}$, evaporation $\mathrm{q}_{\mathrm{e}}$, and possible heating of the vapour phase above saturation $q_{v}$. The definition of $f\left(\alpha_{L}\right)$ used by Fluent is such that $f\left(\alpha_{L}\right)=0$ when the liquid volume fraction $\alpha_{\mathrm{L}}$ in the near-wall cell is below 0.2 . The correlations used to determine the heat transfer rates are listed briefly in Table 2.

Table 2: Boiling model correlations used in the simulations

Term Correlation name

Bubble generation

Steam-Water heat transfer coefficient Hughmark

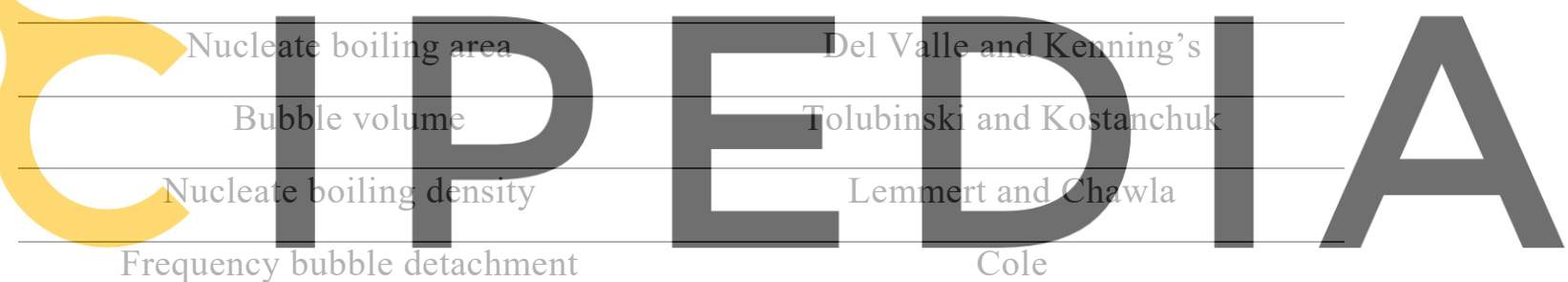

Frequency bubble detachment

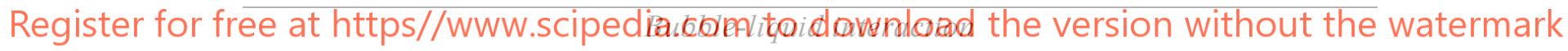

\begin{tabular}{cc}
\hline Drag & Tomiyama \\
\hline Inertia & $\mathrm{C}_{\mathrm{VM}}=0.5$ \\
\hline Lift & Moraga \\
\hline Wall lubrication & Antal \\
\hline Turbulent dispersion & Lopez de Bertodano \\
\hline Turbulence interaction & Sato \\
\hline
\end{tabular}

It should be noted that the boiling correlations listed in Table 2 are only strictly valid within the range of conditions for which they were calibrated for. Since none of these works was done specifically for RPV analysis at the chosen conditions, the results obtained with these boiling models should be taken with caution. The correlations selected in the current 
analysis are based on the sensitivity studies performed in [8] to address CHF in a vertical rod bundle.

Other numerical parameters used in the model are listed in Table 3.

Table 3: Model and numerical schemes used in the simulations

\begin{tabular}{cc}
\hline Turbulence model & $\begin{array}{c}\text { k- } \omega \text { SST } \\
\text { Production limiter, Kato Launder and low } \\
\text { Reynolds corrections } \\
\text { Mixture model }\end{array}$ \\
\hline Solver & $\begin{array}{c}\text { Phase-coupled SIMPLE } \\
\text { Algebraic Multi-Grid with 1 pre-sweep } \\
\text { and 2 post-sweeps }\end{array}$ \\
\hline Gradient & Least-squares cell-based \\
\hline Spatial interpolation & Second order upwind (momentum and \\
energy) \\
\hline Temporal discretization \\
Time step \\
First order upwind (turbulence and volume \\
fraction) \\
\hline Bounded second order upwind \\
$0.03-0.1 \mathrm{~s}$
\end{tabular}
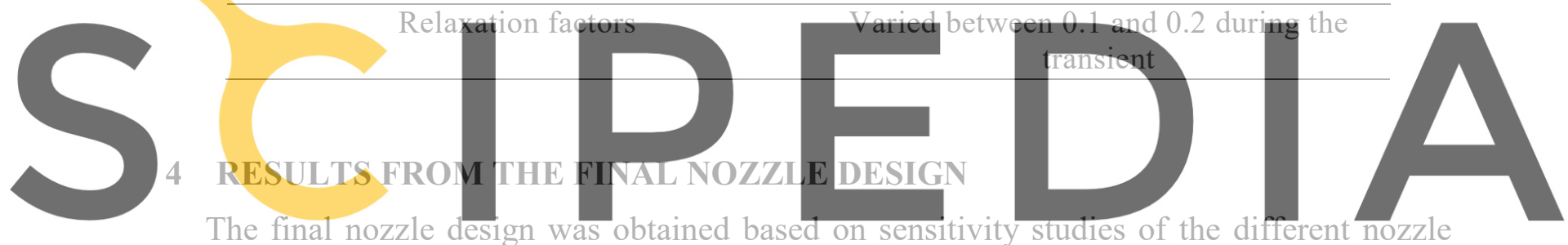

The final nozzle design was obtained based on sensitivity studies of the different nozzle Register for free.at prattps/dwsw. Apcipedia.com to download the version without the watermark

- The cooling fiow shouid be designed to induce a flow pattern rising upwards and parallel to the RPV walls. This implies that the nozzles should be oriented pointing upwards. A downwards orientation is not recommended.

- The largest heat fluxes are expected at the junction between the bottom cap of the RPV and the vertical walls. Thus, larger cooling is required in this region.

- Locating multiple nozzles close to each other can lead to stagnation points at the region where the nozzle flow collides, leading to localized hot-spots.

The final nozzle design is presented in Figure 5. A single central nozzle is proposed to cool the entire bottom cap of the vessel. This prevents the formation of stagnation regions and hotspots created when several jets are located in this area. Due to the large area cooled by the central nozzle, a large flow rate of $140 \mathrm{~m}^{3} / \mathrm{h}$ is proposed.

At the vertical walls, a ring of 32 nozzles injecting a total flow of $1120 \mathrm{~m}^{3} / \mathrm{h}$ is proposed. The nozzles are oriented towards the RPV walls. The proposed location is slightly below the change in curvature between the bottom cap and the vertical walls of the RPV. This is done to 
force the flow from the central nozzle to continue flowing upwards instead of being deflected downwards when reaching the bend. The larger number of nozzles and flow rates proposed for this region are motivated by the larger heat fluxes expected to result from the focusing effect of a buoyant metal layer.
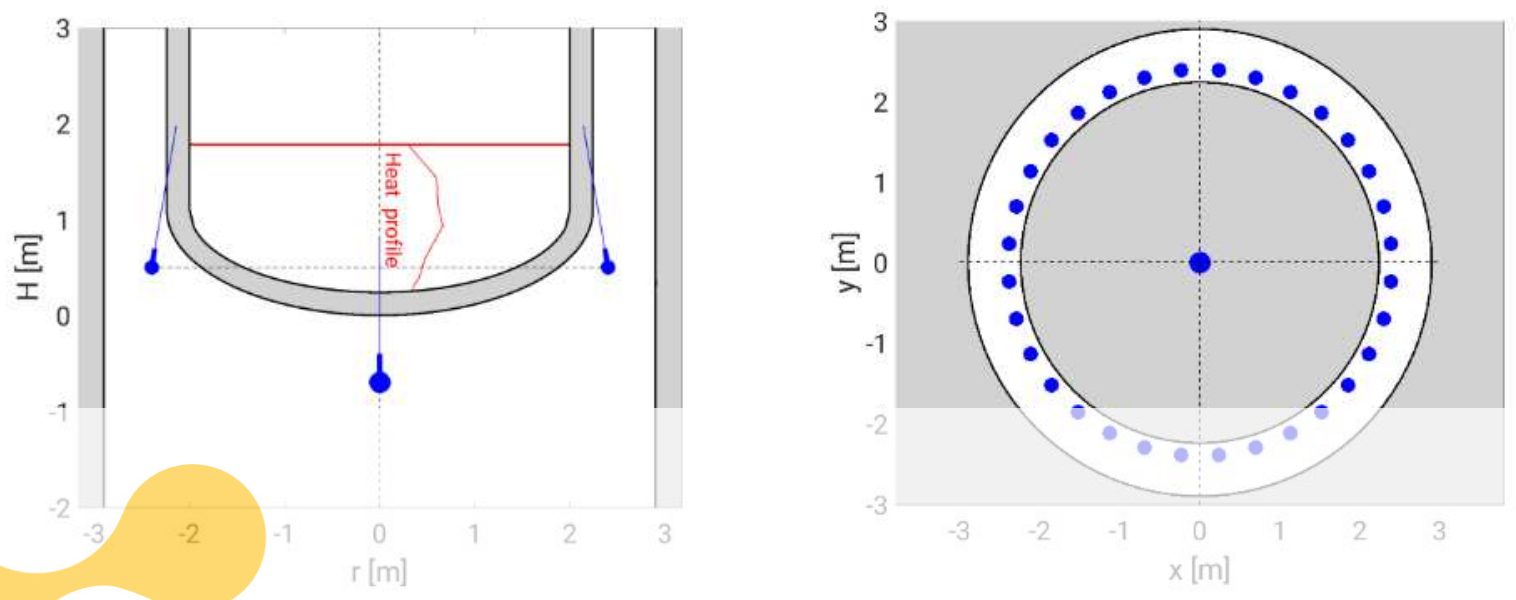

Figure 5: Location and direction of the nozzle rings proposed for the final nozzle design

The simulation run with an outlet nozzle temperature of $117^{\circ} \mathrm{C}$ is presented in Figure 6. vessel walls. The wall temperatures are also la
temperature to $80^{\circ} \mathrm{C}$ learls to a much lower ste of the heat from the $\mathrm{R}$

steam. Reducing the of

(Figure 8). Based on these results, the cooling s
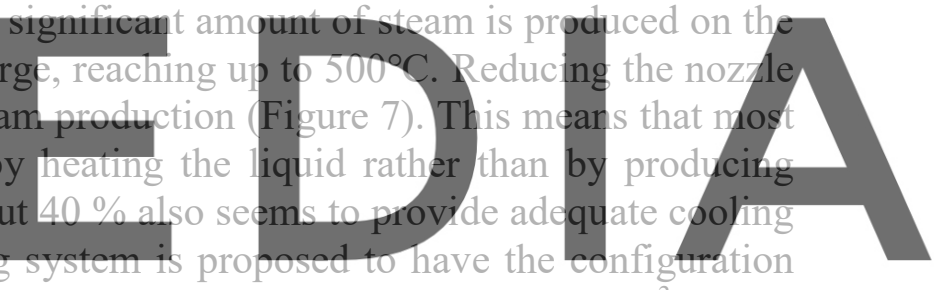

presented in Figure 5, a nozzle temperature of $80^{\circ} \mathrm{C}$, and a total flow rate of $740 \mathrm{~m}^{3} / \mathrm{h}$. The

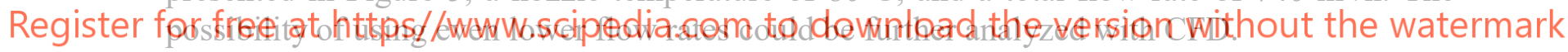

Regarding the flow pattern, we can see in Figure 7 and Figure 8 that the central nozzle is able to cover the entire bottom cap of the RPV and maintain it at a relatively low temperature. The nozzle ring plays an important role in (i) cooling the region where the largest heat fluxes are observed, and (ii) forcing the flow from the central nozzle to continue rising upwards, inducing a large-scale circulation pattern in the pool. 


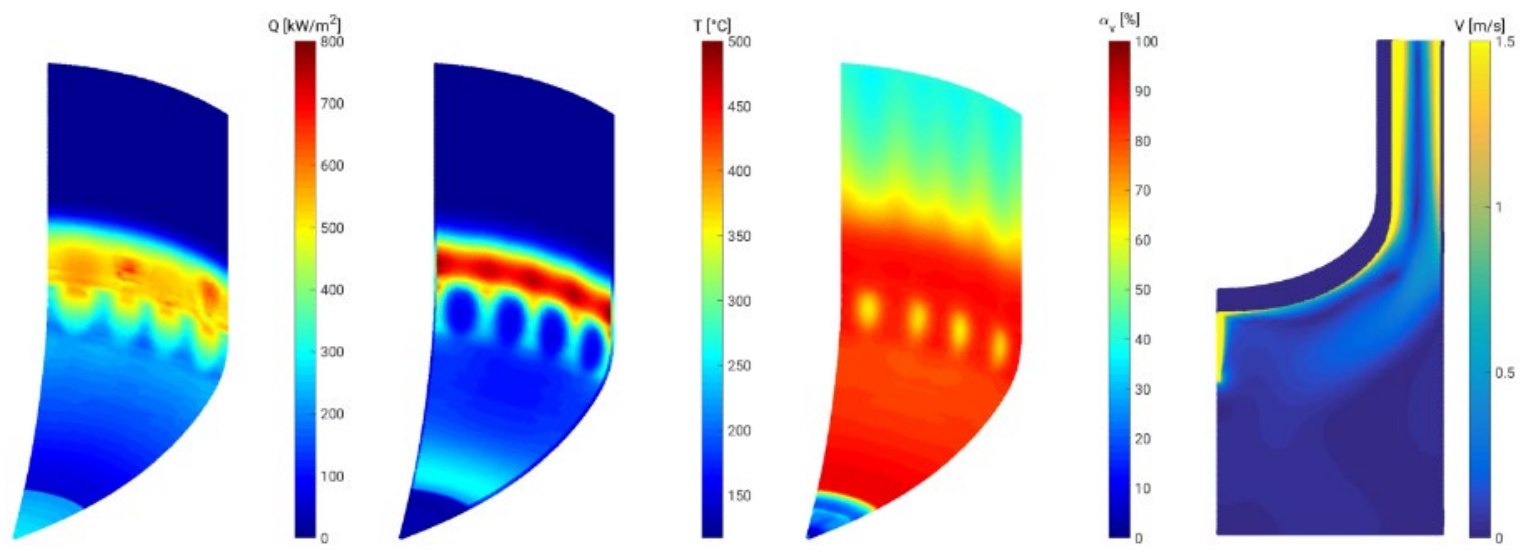

Figure 6: Final nozzle design, $\mathrm{T}=117^{\circ} \mathrm{C}, \dot{m}_{\text {tot }}=1260 \mathrm{~m}^{3} / \mathrm{h}$. Plot time $=1850 \mathrm{~s}$. Heat flux $\mathrm{Q}$, wall temperature $\mathrm{T}$, steam volume fraction $\alpha$ and velocity $\mathrm{V}$.

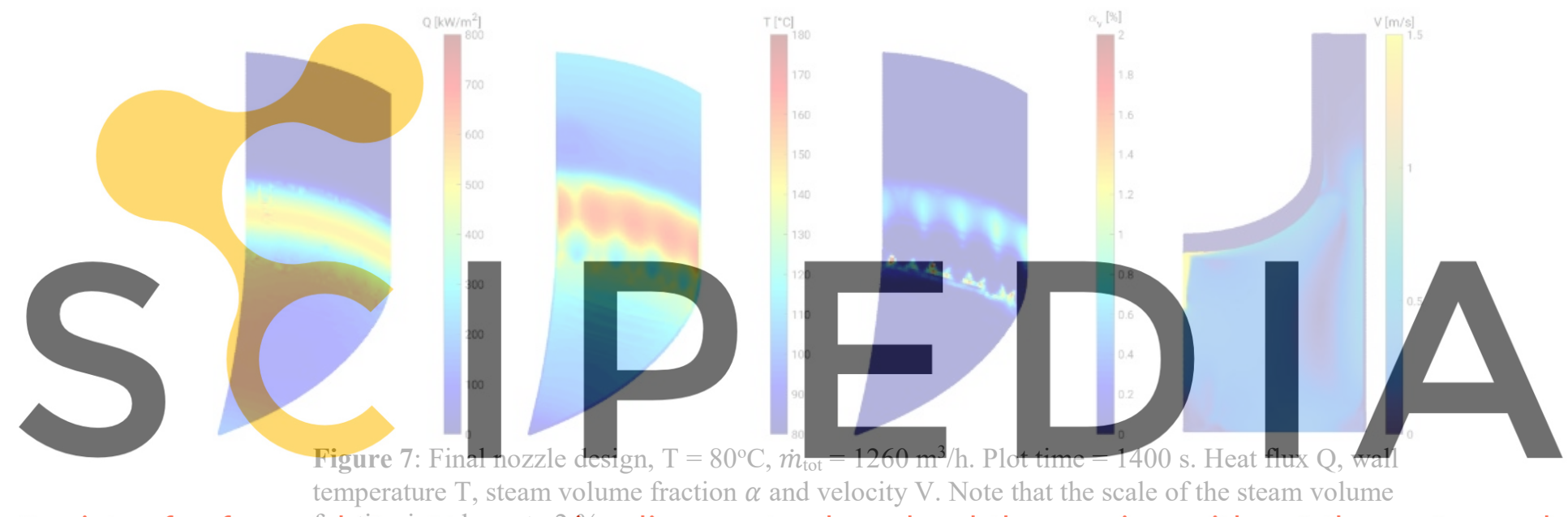

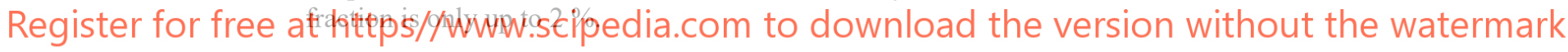
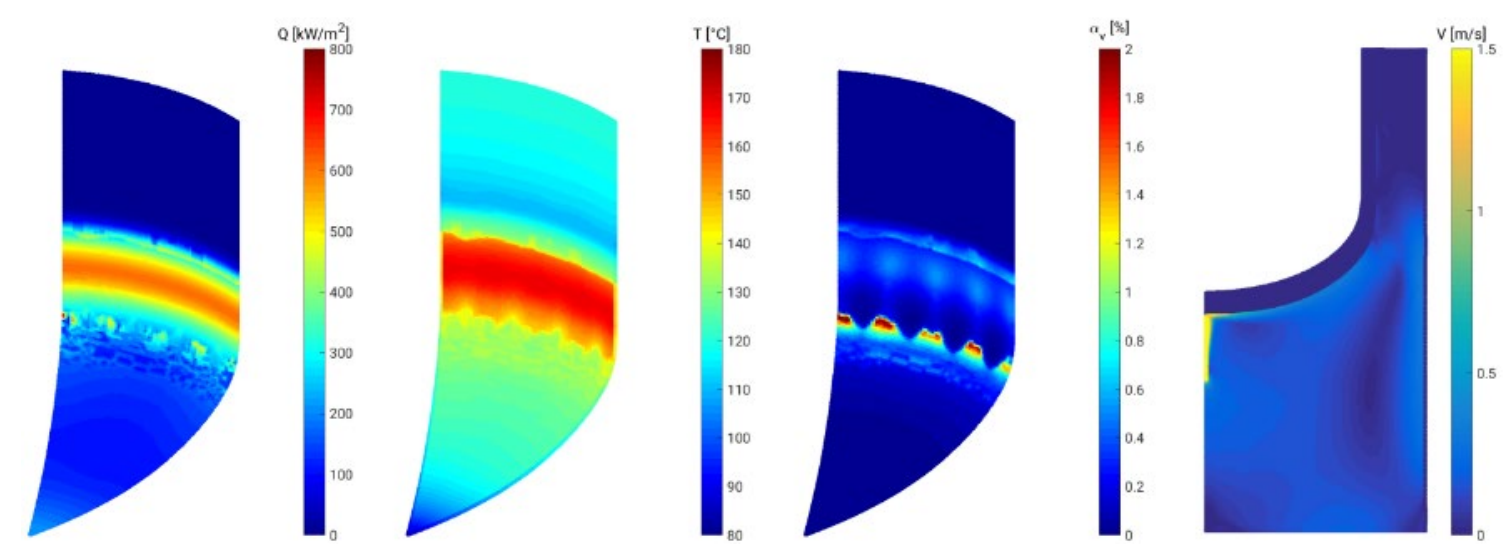

Figure 8: Final nozzle design, $\mathrm{T}=80^{\circ} \mathrm{C}, \dot{m}_{\text {tot }}=740 \mathrm{~m}^{3} / \mathrm{h}$. Plot time $=1400 \mathrm{~s}$. Heat flux Q, wall temperature $\mathrm{T}$, steam volume fraction $\alpha$ and velocity $\mathrm{V}$. Note that the scale of the steam volume fraction is only up to $2 \%$. 
The evolution of the heat flux with respect to time is presented in Figure 9 for all the cases analyzed with the final nozzle design. We can see that the simulations have not yet reached a steady-state in which the heat flux stops varying over time. Longer simulation times would be required for this. However, the results presented in Figure 6 to Figure 8 and the heat balance considerations presented in Section 2 support the conclusion that the current proposed configuration with $80^{\circ} \mathrm{C}$ and $740 \mathrm{~m}^{3} / \mathrm{h}$ will provide a sufficient cooling of the RPV.

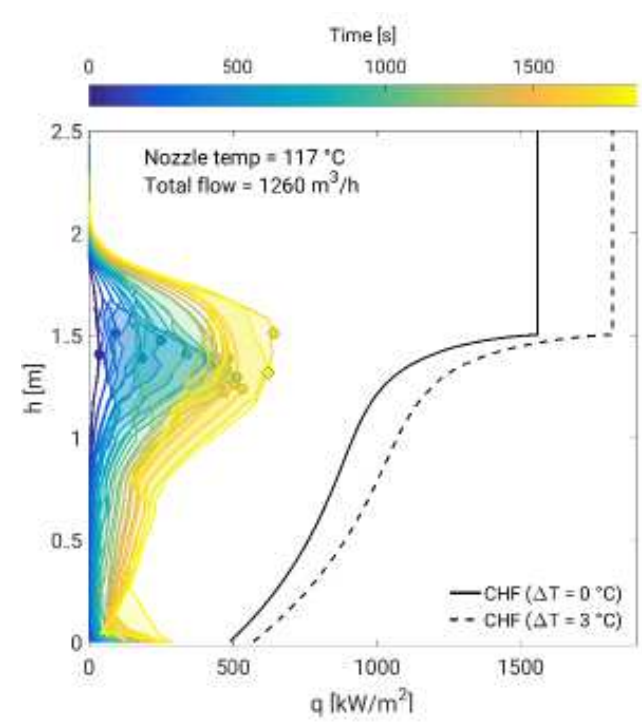

(a)

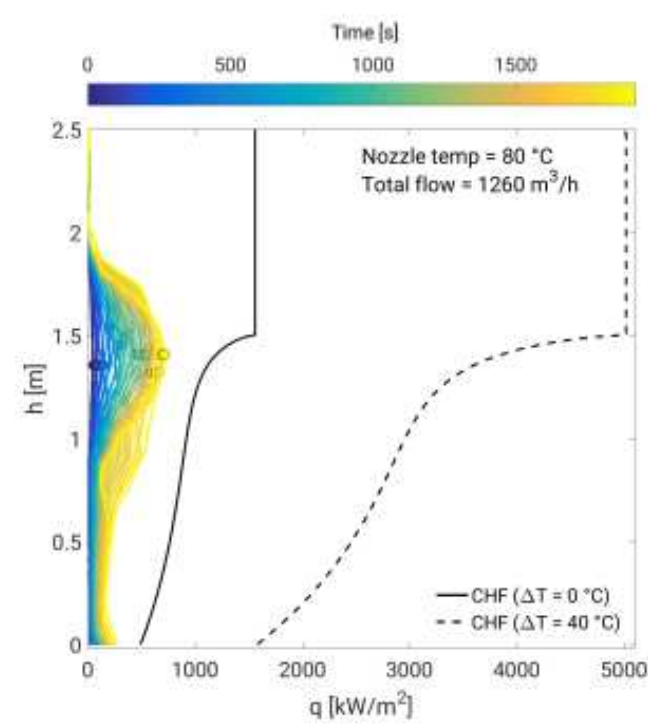

(b)

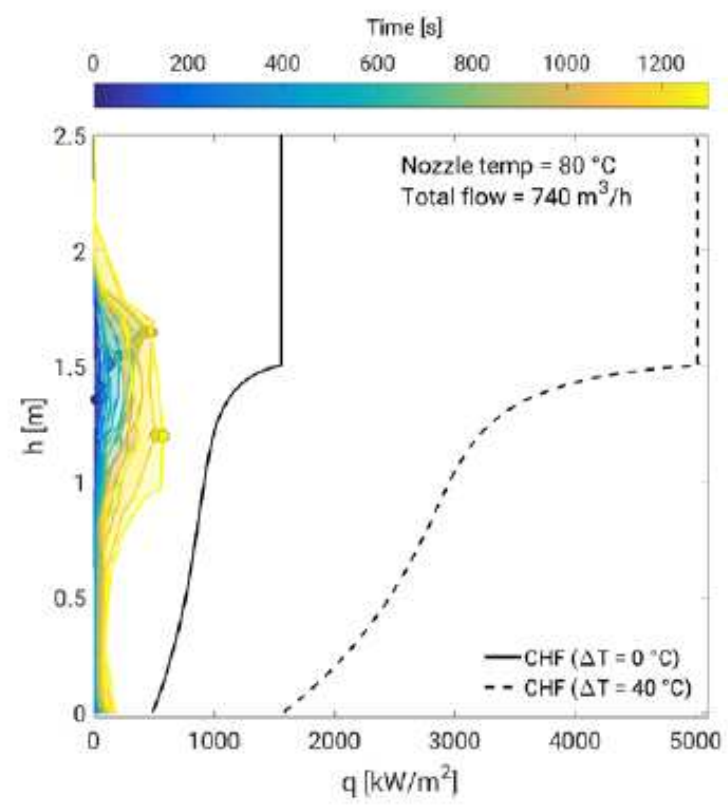

(c)

Figure 9: Heat flux along the vessel walls as a function of time and compared to the Critical Heat Flux (CHF) estimate from (2). (a) $117^{\circ} \mathrm{C} \mathrm{(b)} 80^{\circ} \mathrm{C}$ and (c) $80^{\circ} \mathrm{C}$ with $40 \%$ less cooling flow. 


\section{SUMMARY}

The goal of this work was to design a nozzle system around the RPV which would ensure successful melt retention during a severe accident in a VVER-1000 reactor. In order to do this, CFD simulations were run in ANSYS Fluent 19.1 assuming a constant pressure of 2 bar $\left(120^{\circ} \mathrm{C}\right.$ saturation temperature) and using different nozzle locations, flow rates, cooling temperatures, etc. The sensitivity studies showed that the most efficient cooling can be achieved by inducing a parallel flow rising along the RPV walls.

The proposed final design is presented in Figure 5. It consists of a central nozzle below the RPV (to cool the bottom cap of the RPV) and 32 nozzles at the region where the vertical walls of the RPV walls begin (to cool the region where the RPV walls get thinner and where larger heat fluxes are expected). Using a total cooling flow rate of $740 \mathrm{~m}^{3} / \mathrm{h}$ and an outlet nozzle temperature of $80^{\circ} \mathrm{C}$ enabled an efficient cooling with minimal production of steam and not reaching the Critical Heat Flux (CHF). A larger outlet temperature of $117^{\circ} \mathrm{C}$, showed significant production of steam, even when using a cooling flow rate of $1260 \mathrm{~m}^{3} / \mathrm{h}$.

In future work the model will be validated for the particular system.

\section{REFERENCES}

[1] Sakashita, H., Ono, A. and Nyui, J. Critical heat flux and near-wall boiling behaviors in saturated and subcooled pool boiling on vertical and inclined surfaces. Journal of Nuclear Science and Technology (2009) 46(11):1038-1048

[2] Celata, G.P. and Mariani, A. Critical heat flux, post-dryout and their augmentation. ENEA-Dipartimento Energia Centro Rlcerche Casaccia, Roma.

[3] Joint Research Center (JRC), JRC Technical Report - In-Vessel Melt Retention (IVMR) Analysis of a VVER-1000 NPP. EUR 27951 EN, 2016

[4] Theofanous, T.G. and Syri, S. The coolability limits of a reactor pressure vessel lower head. Nuclear Engineering and Design (1997) 169:59-76

[5] Theofanous, T.G. et al. In vessel coolability and retention of a core melt. Nuclear Engineering and Design (1997) 169:1-48

[6] Pothukuchi, H. et al. CFD modeling of critical heat flux in flow boiling: Validation and assessment of closure models. Applied Thermal Engineering (2019) 150:651-665

[7] Zhang, Y. et al. Numerical prediction of CHF based on CFD methodology under atmospheric pressure and low flow rate. Applied Thermal Engineering (2019) 149:881888

[8] Zhang, R. et al. Effects of turbulence models on forced convection subcooled boiling in vertical pipe. Annals of Nuclear Energy (2015) 80:293-302

[9] Ono, A. and Sakashita, H. Measurement of surface dryout near heating surface at high heat fluxes in subcooled pool boiling. International Journal of Heat and Mass Transfer (2009) 52:814-821 